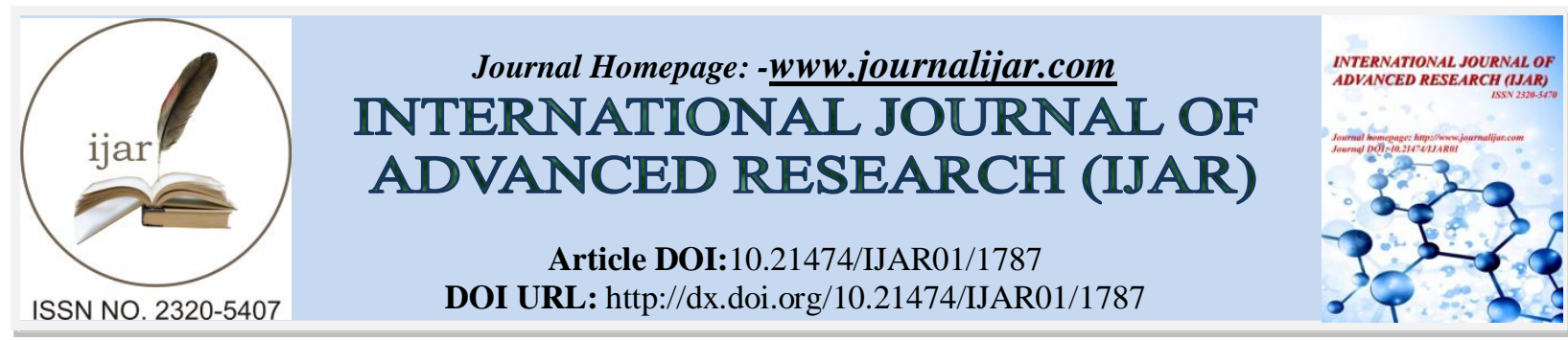

RESEARCH ARTICLE

\title{
THE GROWTH HORMONE DEFICIENCY SHORT STATURE IS THE PREDOMINANT TYPE AMONG YOUNG SCHOOL GIRLS IN GAZA, PALESTINE.
}

\author{
Hussam Rashed ${ }^{1}$, Nehad El-Yazji ${ }^{2}$ and Wael El-Sayed ${ }^{3, *}$. \\ 1. Shifaa hospital, Laboratory and blood bank, Gaza, Palestine. \\ 2. University ofEl Aqsa,Faculty of Science, Department of Biology, Gaza, Palestine. \\ 3. University of Ain Shams, Faculty of Science, Department of Zoology, Abbassia 11566, Cairo, Egypt.
}

\section{Manuscript Info}

\section{Manuscript History}

Received: 12 August 2016

Final Accepted: 22 September 2016

Published: October 2016

Key words:-

GH, IGF-1, IGFBP3, FSH, estradiol, short stature

\section{Abstract}

The purpose of this study was to identify the type of short stature (SS) and to survey relationships between estradiol, ghrelin, osteocalcin, insulin, GH, IGF-1, IGFBP-3, TSH, FSH, LH, prolactin, progesterone, minerals and SS among secondary school girls, Gaza, Palestine. Nonexperimental case control study design was used to collect data from 90 subjects with SS (case group), and 90 subjects with normal stature (control group). After 12 hour fasting, blood samples were collected.There were highly significant reductions in stature, body weight, GH, IGF-1, IGFBP-3, and FSH levels in case girls compared to control.Significant elevations in the activities of alanine aminotransferase(ALT) and alkaline phosphatase (ALP) were reported in cases compared to controls. In addition, there was a significant correlation between insulin and height and between IGF-1 and ghrelin in case girls. Ghrelin, osteocalcin, LH, prolactin, progesterone and TSH were not correlated with short stature in young females (15-16y). Growth related hormones could serve as a biomarker in the diagnosis of short stature. Elevations in ALT and ALP without changes in phosphorus suggest liver problem and needs further investigation and attention. Growth hormone deficiency SS is the predominant SS type in Gaza school girls.

Copy Right, IJAR, 2016,. All rights reserved.

\section{Introduction:-}

Early identification of short stature (SS) patients is of great importance for proper and effective treatment. The association between short stature and many serious diseases such as cardiovascular disease (CVD), cancer, stroke and Alzheimer makes early diagnosis even more important. Short stature is affected by many hormones and other factors. Two of the most common and significant types of SS are idiopathic short stature (ISS) and growth hormone deficiency (GHD) [1]. It is the long bones of the skeleton, primarily the legs, which contribute the greatest tofinal body height. Hormonal changes during puberty trigger the onset of the adolescentgrowth spurt [2]. Sex steroids are of great importance in normal growth, especially during puberty, when they control initiation, maintenance and cessation of the pubertal growth spurt [3].It is now accepted that estrogen is the sex steroid of crucial importance in both sexes regarding growth acceleration and eventual fusion of the growth plates. It is known that there is a diurnal variation in the levels of estradiol and that the levels increase through pubertal stages [1]. In women, estrogens are produced by the mature ovarian follicle, the placenta and the corpus luteum. Their synthesis is stimulated by FSH 
and LH.The sex steroids act both locally in the growth plate and systemically via the GH/IGF-1 axis. GH is perhaps the single most critical determinant of post-natal linear growth and it mainly acts by increasing the proliferation of chondrocytes directly and in concert with IGF-1.

GH is secreted in pulsatile and intermittent manner from anterior pituitary gland under the control of growthhormone secretagogues (GHSs),growth hormone releasing hormone(GHRH) and somatostatin[4]. GHSs are small synthetic molecules that stimulate the release of GH through a G protein - coupled receptor in the pituitary gland. GH secretion can also be induced by ghrelin, which has an important role in proliferation and differentiation of osteoblasts [5]. The physiological role of ghrelin, the native substrate for the GH-releasing peptide (GHRP) receptor, is not fully elucidated, but high GH responses are induced by GHRP or Ghrelin infusion and these act synergistically to GHRH stimuli [6].The most powerful external physical stimuli of GH release are exercise and sleep.Ghrelin is a natural ligand of the G-protein coupled growth hormone secretagogue receptor type 1a (GHS-R1a)[7]. Ghrelin has diverse physiologic functions and is involved in energy-homeostasis, glucose and lipid metabolism, adipogenesis, food intake as well as in the stimulation of bone formation [8].GH stimulates growth at the growth plate by increasing cell size rather than increasing cell number [9].The somatotropic effect of GH is mediated partially through stimulation of the synthesis of IGF-I and IGFBP-3 in the liver and at growing cartilage where it acts as a local paracrine-autocrine hormone[10]. IGF-I is a polypeptide belonging to the same family of growth factors as insulin. Serum IGF-I concentrations reflect the GH concentrations over 24 hours. GH antagonizes the actions of insulin resulting in glucose intolerance and hyperinsulinemia. In contrast, IGF-I has insulin-like effects by enhancing peripheral glucose uptake[11].Low IGFBP-3 and IGF-1 levels are observed in GH deficiency or GH resistance. If acquired in childhood, these conditions result in short stature.

Osteocalcin is synthesized exclusively by the osteoblasts and stored in the bone mineral matrix as hydroxyapatite crystals. Osteocalcin, or bone Gla protein, serves as a marker of bone formation [12]. Osteocalcin declined when height velocity decreased, although bone maturation progressed at a steady rate [13].Consequently, only a small amount of newly produced osteocalcin is released into the circulation but it is sufficient to reflect the spillover of osteoblast activity. Osteocalcin is the ideal bone biomarker to measure because of its exclusive specificity to the process ofbone formation compared to the procollagen I extension peptides found also in the skin and soft tissues[14].

SS is normally diagnosed by the clinical picture, which is assessed by the physician beside the determination of GH. Thisstudy is to the best of knowledge the first one in Gaza to investigate the correlations between estrogen, GH, IGF-1 and IGFBP-3 as well as many other factorsandSSamong a group of young females. It is also the first study to survey the type of SS common among school girls in Gaza. This will help in the early detection of SS patients and in the prediction of SS-associated serious diseases.The findings of the study will also help developing insight into etiological profile, age-sex distribution and the magnitude of SS in Gaza.

\section{Subjects and methods:- \\ Subjects:-}

The target population in the present study was girls with short stature aged between 15 - 16 years old who reside in Gaza City, Palestine. Ninety young girls with short stature were randomly selected from secondary schools. Ninety young girls of the same age with normal stature were selected in parallel as control group. Height and weight were measured, and body mass index was calculated.The girls in the short stature group had heights less than 3rd percentile or height SDS $<-2$ for age and sex according to WHO while control girls had normal range ofheights for age and sex with annual growth velocity. All the girls were otherwise healthy in terms of chronic or systemic disorders (not diabetic, not rheumatologic, did not take glucocorticoids, do not suffer chronic kidney disease). The study protocol was approved by the local ethics committee (Palestinian National Authority - MOH - Helsinki Committee)(No: PHRC/HC/39/14, Date: 28/2/2015) and informed consent was obtained from all parents.

\section{Protocol:-}

Non-experimental case control study design was used in the present study. The collected blood samples were examinedfor estradiol, FSH, LH, PRL, progesterone, TSH, ghrelin, osteocalcin, insulin, GH, IGF-1, IGFBP-3, calcium, phosphorus, magnesium, and liver function tests (AST, ALT) and ALP activities. All samples were analyzed in Ministry of Health (MOH) laboratory (Shifa Hospital - Chemistry Department) and Biolab medical laboratory. 


\section{Blood sample collection:-}

The target population was determined, schools were visited by the researcher, and the study objectives were explained to the headmasters, staff and the selected girls and their parents. The researcher advised all girls the day before blood sample collection to be in a fast condition. Blood samples were collected in the early morningand in the folliculate phase $\left(12^{\text {th }}\right.$ day of the beginning of the menstruation) because of high beak level of estradiol.Before sampling, each girl was requested to do exercise for about 15 minutes, which is a prerequisite for GH assay. Taking into consideration safety rules and quality assurance guidelines, $10 \mathrm{~mL}$ venous blood were collected from each girl.Three $\mathrm{mL}$ blood were placed into plastic tube containing $15 \mu \mathrm{L}$ protease inhibitor (pefabloc) supplied by R\&D (USA) for ghrelin assay. One $\mathrm{mL}$ of serum with protease inhibitor was placed in plastic tube, $10 \mu \mathrm{L}$ of $5 \mathrm{~N}$ HCL were added and samples were stored at $-20 \pm 5^{\circ} \mathrm{C}$ for serum ghrelin assay.Three mLof blood were placed in ethylenediaminetetraacetic acid(EDTA) tube for plasma osteocalcin. The remained quantity of blood was placed in plain vacutainer tube.All blood samples were kept on ice before they were transported back to the laboratory for further processing. Serum samples were obtained by centrifugation at $3000 \mathrm{rpm}$ for 10 minutes. Each serum sample was split into two parts and stored at $\left(-20^{\circ} \mathrm{C}\right)$ to be examined later.

\section{Laboratory tests:-}

Ghrelin, osteocalcin, insulin, TSH, estradiol, FSH, LH, PRL, progesterone, GH, IGF-1 and IGFBP-3 quantitative determinations were performed using Enzyme Immunoassay (EIA) kits [ghrelin (EMD Millipore, Germany), osteocalcin (R\&D, USA), insulin, TSH, estradiol, FSH, LH, PRL, progesterone, GH, IGF-1 and IGFBP-3 (DRG, Germany)] according to manufacturer instructions using stat fax-2100 Awareness technology, instrument (USA). Assays for $\left[\mathrm{Ca}^{2+}\right.$ (Elitech, France), $\mathrm{Mg}^{2+}$ (Diasys, Germany), P(AMS Globe Diagnostic Systems, Italy), ALP, AST, and ALT(AMS Globe Diagnostic Systems, Italy)] were performed using standard kinetic and colorimetric methods.

\section{Statistical analysis:-}

Data were analyzed using SPSS (Statistical Package for the Social Science Inc. Chicago, Illinois USA, version 22) statistical package.Simple distribution of the study variables and the cross tabulation were applied.The independent sample t-test procedure was used to compare means of quantitativevariables by the separated cases into two qualitative groups.Pearson's correlation test wasapplied and regression was determined.The results were considered significant when $P<0.05$.

\section{Results:-}

The study sample size was 180 female participants. In this study, there was no statistically significant difference in age or BMI between case and control girls. In addition, there were significant decreases $(P<0.001)$ in height and weight in case girls as compared to control girls, Figure 1.As for the hormonal profile, the results revealed that there were no statistically significant differences in estradiol, ghrelin,prolactin, LH, progesterone, TSH, insulin or osteocalcin levels in serum between case and control girls as shown in Table $\mathbf{1}$.

Table 1:-Average of serum levels of hormones for cases and controls.

\begin{tabular}{|l|c|c|}
\hline & Controls & Cases \\
\hline Estradiol (pg/ml) & $75.51 \pm 4.96$ & $74.54 \pm 5.10$ \\
\hline Ghrelin $(\mathbf{p g} / \mathbf{m l})$ & $442.49 \pm 15.37$ & $451.64 \pm 16.49$ \\
\hline Osteocalcin $(\mathbf{n g} / \mathbf{m l})$ & $58.12 \pm 1.32$ & $55.91 \pm 1.56$ \\
\hline PRL $(\mathbf{n g} / \mathbf{m l})$ & $5.12 \pm 0.27$ & $5.64 \pm 0.30$ \\
\hline LH $(\mathbf{m I U} / \mathbf{m l})$ & $5.21 \pm 0.26$ & $5.80 \pm 0.31$ \\
\hline FSH $(\mathbf{m I U} / \mathbf{m l})$ & $7.89 \pm 0.26$ & $5.74 \pm 0.27^{*}$ \\
\hline Progesterone $(\mathbf{n g} / \mathbf{m l})$ & $2.98 \pm 0.26$ & $2.67 \pm 0.27$ \\
\hline IGF-1 $(\mathbf{n g} / \mathbf{m l})$ & $207.78 \pm 8.77$ & $167.22 \pm 9.81^{*}$ \\
\hline IGFBP-3 (ng/ml) & $3164.44 \pm 70.95$ & $2837.78 \pm 56.04^{*}$ \\
\hline GH $(\mathbf{n g} / \mathbf{m l})$ & $4.31 \pm 0.13$ & $1.53 \pm 0.12^{*}$ \\
\hline Insulin $(\boldsymbol{\mu I U} / \mathbf{m l})$ & $18.92 \pm 0.60$ & $19.08 \pm 0.59$ \\
\hline TSH $(\mathbf{m I U} / \mathbf{L})$ & $1.43 \pm 0.07$ & $1.52 \pm 0.10$ \\
\hline
\end{tabular}

PRL: prolactin, LH: luteinizing hormone, FSH: follicle stimulating hormone, IGF-1: insulin like growth factor 1, IGFBP-3: insulin like growth factor binding protein 3, GH: growth hormone, TSH: thyroid stimulating hormone. * Significant difference as compared to controls $(P<0.05, \mathbf{n}=90)$. 


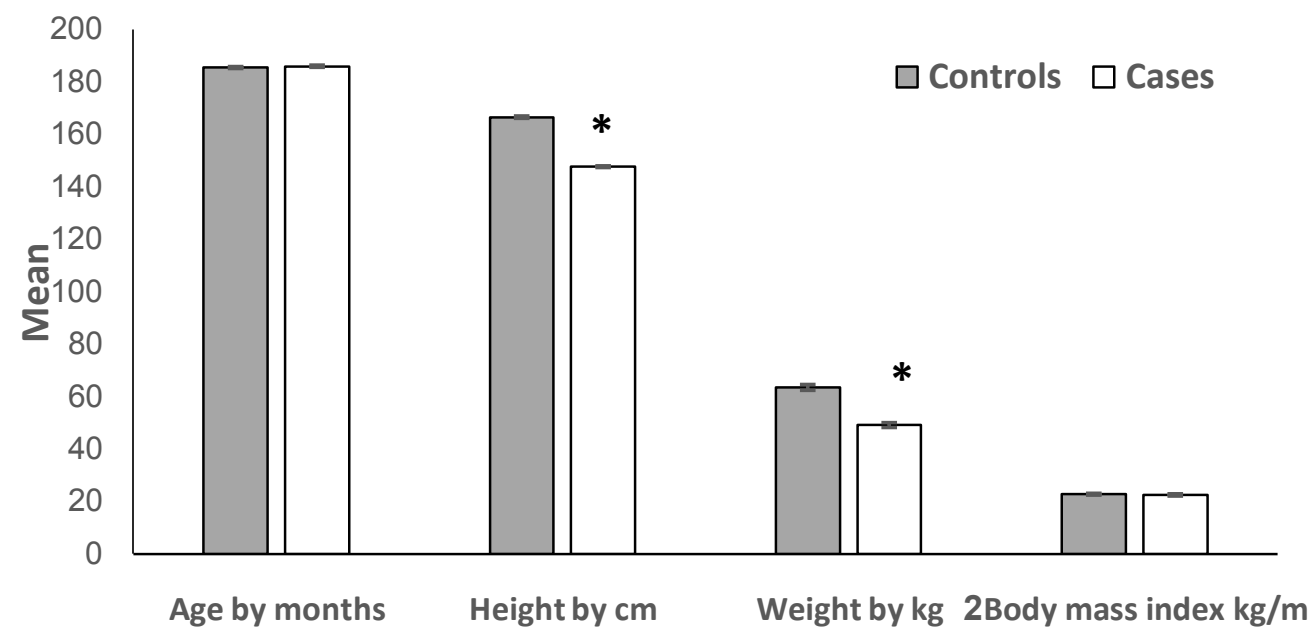

Figure 1:-Average age, height, weight and body mass index for cases and controls * Significant difference as compared to controls $(P<0.05, \mathrm{n}=90)$.

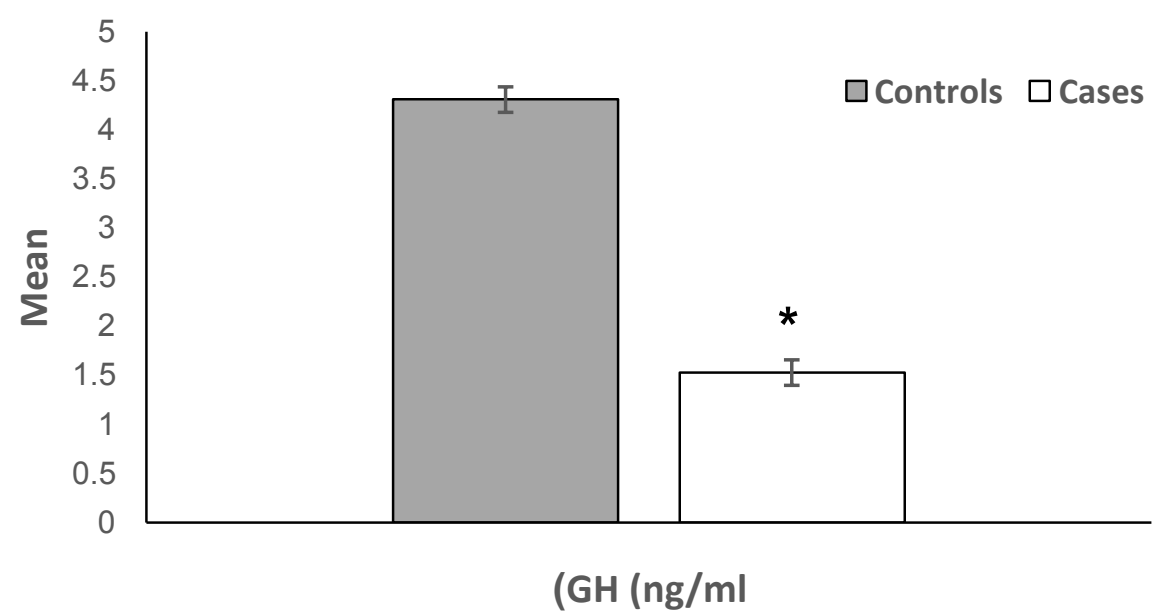

Figure 2:-Average of $\mathrm{GH}$ for cases and controls.

* Significant difference as compared to controls $(P<0.05, \mathbf{n}=90)$.

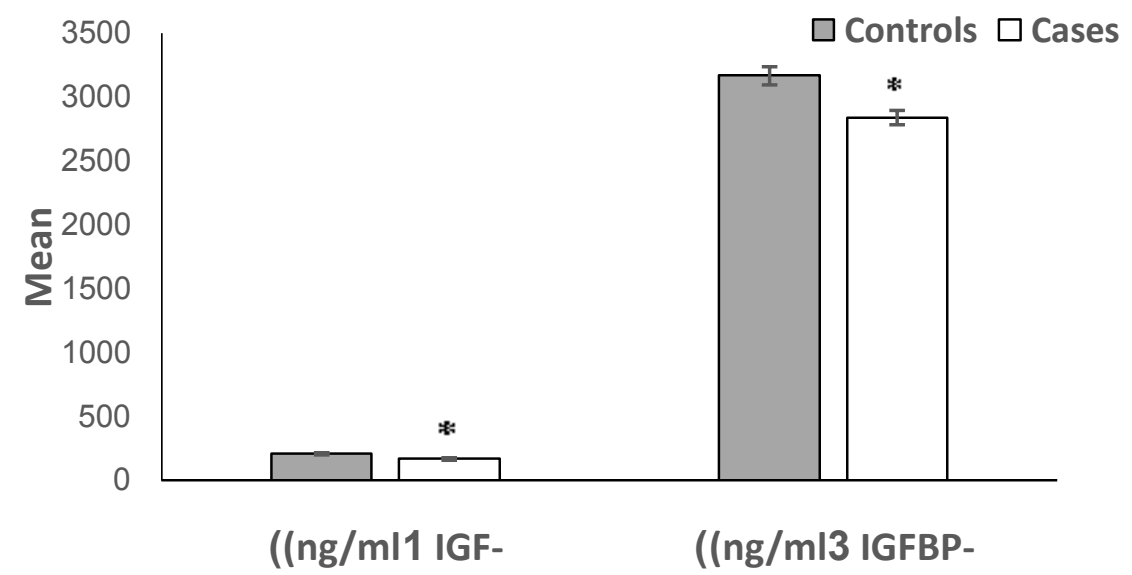

Figure 3:-Average of IGF-1 and IGFBP-3 for cases and controls.

* Significant difference as compared to controls $(P<0.05, n=90)$. 
On the other hand, there was a significant decrease in serum FSH level $(P=0.001$, Table 1) in case girls when compared to control girls, GH level $(P<0.001)$ (Table 1 andFigure 2), IGF-1 level $(P=0.002)$, and IGFBP-3 level $(P<0.001)$ (Table 1andFigure 3). There was a significant increase in serum ALT activity $(P=0.002)$ and ALP $\operatorname{activity}(P=0.010)$ in case girls as compared to control girlsas shown in Table 2 . Moreover, there were no significant differences in serum phosphorus, magnesium or calcium between case and control girls as shown in

Table 2.

Table 2:- Average serum activity of enzymes and levels of minerals for cases and controls.

\begin{tabular}{|l|c|c|}
\hline & Controls & Cases \\
\hline AST (U/L) & $16.07 \pm 0.51$ & $15.92 \pm 0.65$ \\
\hline ALT (U/L) & $21.51 \pm 0.71$ & $25.07 \pm 0.88^{*}$ \\
\hline ALP (U/L) & $244.52 \pm 8.43$ & $286.50 \pm 13.76^{*}$ \\
\hline Magnesium (mg/dl) & $2.14 \pm 0.02$ & $2.14 \pm 0.02$ \\
\hline Phosphorus (mg/dl) & $4.01 \pm 0.04$ & $3.98 \pm 0.05$ \\
\hline Calcium (mg/dl) & $10.32 \pm 0.04$ & $10.26 \pm 0.05$ \\
\hline
\end{tabular}

AST: aspartate aminotransferase, ALT: alanine aminotransferase, ALP: alkaline phosphatase

* Significant difference as compared to controls $(P<0.05, \mathbf{n}=90)$.

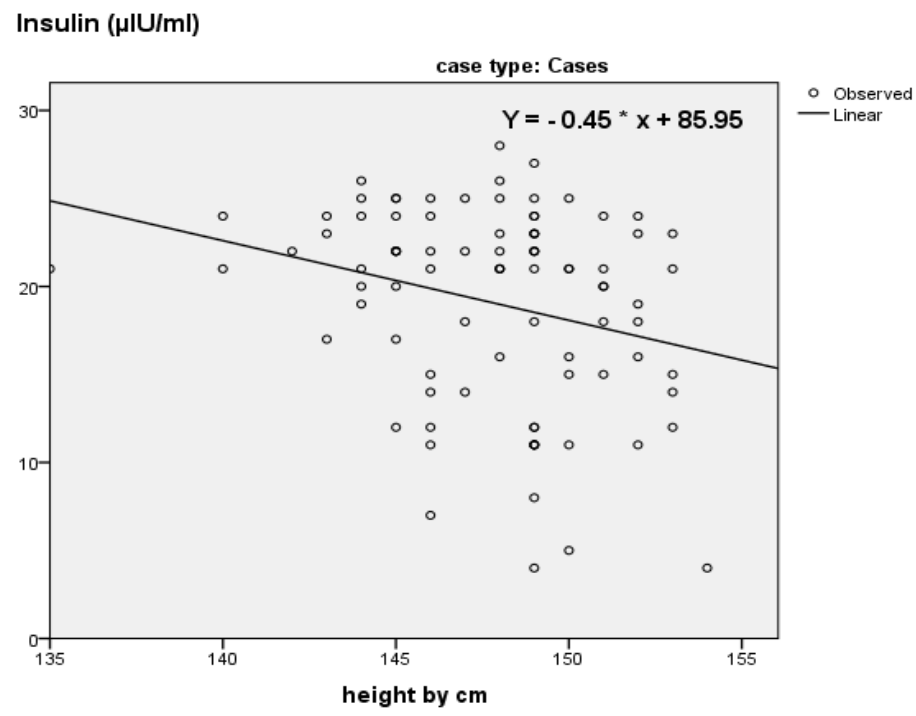

Figure 4: Correlation between height and insulin among cases.

\section{Correlation between different parameters in case girls:-}

The results of the study revealed that there was a significant correlation between stature and insulin of cases $\left(\mathrm{R}^{2}=0.072, P=0.01\right)$ as shown in Figure 4.In addition, there were significant correlations between each of the following pairs; $\mathrm{GH}$ and estradiol $(P=0.03), \mathrm{GH}$ andTSH $(P=0.009)$, IGF-1 and ghrelin $(P=0.02)$, IGF-1 and ALT activity $(P=0.04)$, IGF- 1 and ALP activity $(P=0.001)$, IGF- 1 and phosphorus $(P=0.03)$, IGFBP-3 and ALP activity $(P=0.03)$, FSH and LH $(P=0.04)$ andFSH and calcium $(P=0.003)$.

\section{Discussion:-}

As growth is the essential biologic characteristic of childhood, failure of physical growth may be an important sign of diseases. Short stature in itself may be a disability and a cause of distress [15]. Many hormones secreted by the endocrine system control growth. Key hormones are estradiol, TSH, GH, IGF-1 and IGFBP-3. This hormonal network is complex with several interactions, feedback mechanisms and temporal cues [16]. Sex steroids such as estradiol promote height growth in childhood and early puberty and accelerate skeletal maturation and epiphyseal closure in late puberty. Estradiol acts in association with GH and IGF-1 [17].

The current study has been endeavored to investigate the relationship between estrogen,ghrelin, osteocalcin, insulin, TSH, GH, IGF-1, IGFBP-3, FSH, LH, PRL, progesterone and other biochemical factors and short stature.To our knowledge, this is the first study in Gaza, Palestine investigating the relationship between the previously mentioned 
factors and short stature. This study will help developing strategies for treating short children and predicting other short stature associated disturbances.Cases were chosen among secondary school girls aging $15-16$ years. The choice of this particular age rationale was to ensure the full development of body organs especially the ovaries with regular menstrual cycle.Furthermore, the maximum increase of height in girls occurs between 12 and 16 years of age. After this age, growth will be discontinued.

The results showed that there was no statistically significant correlation between estradioland height in case girls at this time of age in the target group. Little is known about the association betweenyoung girl height and $17 \beta$ estradiol. A previous study found a positive correlation between the levels of serum estradiol and bone mas density (BMD) rather than bone length in healthy girls aged 10-15 years [18]. In a study of healthy girls, estradiol concentrations were significantly associated with growth velocity but at age $10-11.5$ years [19].

The results of the study revealed that there was a significant correlation between stature and insulinin case girls, although the level of insulin was not changes in SS case girls. Insulin has been observed to promote birth size, changes in growth during childhood and, in particular, sexual maturation, ovarian steroidogenesis, and production of sex hormone-binding globulin [20]. Thus, several biological mechanisms support an association between adult height and insulin levels. Furthermore, as adult height may reflect lifetime insulin sensitivity. Insulin stimulates the synthesis of sex steroids and inhibits the synthesis of sex hormone-binding globulin, a binding protein that regulates the bioavailability of circulating sex steroids to tissues [21]. It has been suggested that the adolescent growth spurt involves stimulation by insulin and sex steroids [22].

Our results showed that there was a significant decrease in FSH, GH, IGF-1 and IGFBP-3 levels in case girls when compared to control girls.The GH/IGF-1 axis has a critical role in pubertal bone growth. The peak in longitudinal growth velocity is correlated to peak concentrations of GH. GH increases growth at puberty through the stimulation of IGF-1 production [23].The reduction in GH level led to the failure of liver to synthesize both IGF-1 and IGFBP3.IGF-1 stimulates endochondral bone formation and rapidly activates bone turnover. Circulating IGF-1 levels directly regulate bone growth and density, and epidemiological studies have suggested a causal relationship between serum levels of IGF-1 and bone density or bone mass [24].IGFBP-3 has also a direct effect on bone metabolism by stimulating osteocalcin synthesis through osteoblasts and preosteoblasts [25]. Yet the reduction in osteocalcin level in case girls did not achieve a statistical significance in the current study and therefore had not been affected by the reduction in IGFBP-3. Peak IGF-1 and IGFBP-3 levels are reached approximately 2 years after the attainment of PHV, which occurs in girls at about 12-13 years of age[26].

In healthy children serum IGF-1 and IGFBP-3 levels well reflect the endogenous 24-hour GH secretion. These levels have been recognized as useful clinical parameters since they show very little diurnal changes and remain stable [27]. In the blood, IGF-1 forms a complex with IGFBP-3. This complex serves as a circulatory reservoir for IGF-1 [28]. The lack of any major diurnal variation in circulating IGF-1 levels combined with the long half-life of ternary bound IGF-1 and the absence of any major seasonal variation makes IGF-1 a potential candidate for screening of GHD [29]. However, IGF-1 levels are age-dependent, and normal levels may overlap with those observed in GHD during early childhood. IGFBP-3 has the advantage of being age-independent and being a good indicator of GH status. Age independence of IGFBP-3 makes it a useful marker of GH-IGF axis during infancy. The best diagnostic accuracy (sensitivity of $97 \%$ and specificity of 95\%) is however achieved by combining IGF-1 and IGFBP-3 assays, which are now replacing GH-based investigations for evaluation and monitoring of disorders of the GH-IGF axis [30, 31].This usefulness was disputed, in a study in Bangkok, Thailand, suggesting that the measurement of IGF-1 and IGFBP-3 cannot be used in diagnosing GHD [32]. The age range in the previous study was 0.9 to 19.9 years where huge fluctuations in IGF-1 and IGFBP-3 are expected.

FSH plays a major role in the deposition, maintenance, and degradation of the skeleton. Therefore, changes in FSH may have a profound effect on bone tissue [33]. FSH regulates the development, growth, pubertal maturation, and reproductive processes of the body. In women, the reduction of FSH has been shown to negatively influence BMD [34].

Since ALP is a marker for osteoblastic activity, growing children have higher levels than fully grown individuals. Cross-sectional studies have demonstrated that the activities of total ALP in plasma parallel the childhood height velocity curve, with highest activities during infancy, smaller increases during puberty (the peak occurring earlier and lower in girls than in boys), and a post pubertal decrease to much lower adult values [35]. The bone mineral 
content showed almost no variation from the age of 7 to 11 in girls. Thereafter a sharp increase occurs. A significant negative correlation between bone mineral content and serum alkaline phosphatase was seen in girls. The coincidence in timing of the height velocity and total ALP peaks during puberty in girls has been confirmed in a longitudinal study [36]. The increase in ALP activity was as a result of hormonal changes and also due to the effect of parathyroid hormone on bone. ALP is the earliest bone marker as it plays an important role in bone formation and resorption. The elevation in ALT activity in case girls suggests a hepatic problem that needs further attention and investigation. Based on the current study results, we think that the major type of SS in Gaza among school girls is the GHD type and therefore, we recommend the combined measurement of IGF-1 and IGFBP-3 as screening test for patients with short stature.

\section{Conflict of interests:-}

None declared.

\section{References:-}

1. Cohen P, Rogol AD, Deal CL, Saenger P, Reiter EO, Ross JL, Chernausek SD, Savage MO, Wit JM. Consensus statement on the diagnosis and treatment of children with idiopathic short stature: a summary of the growth hormone research society, the Lawson Wilkins Pediatric Endocrine Society, and the European Society for Paediatric Endocrinology Workshop. Journal of Clinical Endocrinology and Metabolism $2008934210-$ 4217.

2. Gluckman PD\& Hanson MA. Changing times: the evolution of puberty. Molecular and Cellular Endocrinology 2006254-255 26-31.

3. Balthazart J, Cornil CA, Charlier TD, Taziaux M, Ball GF.Estradiol, a key endocrine signal in the sexual differentiation and activation of reproductive behavior in quail. Journal of Experimental Zoology. Part A, Ecological Genetics and Physiology2009311323-345.

4. Hindmarsh PC\& Dattani MT. Use of growth hormone in children. Nature ClinicalPractice. Endocrinology and Metabolism 20062260-268.

5. Maccarinelli G, Sibilia V, Torsello A, Raimondo F, Pitto M, Giustina A, Netti C, Cocchi D.Ghrelin regulates proliferation and differentiation of osteoblastic cells. Journal of Endocrinology2005184249-256.

6. Gualillo O, Lago F, Gomez-Reino J, Casanueva FF, Dieguez C. Ghrelin, a widespread hormone: insights into molecular and cellular regulation of its expression and mechanism of action. Federation of European Biochemical Societies letters2003552105-109.

7. Kojima M, Hosoda H, Date Y, Nakazato M, Matsuo H, Kangawa K. Ghrelin is a GH releasing acylated peptide from stomach. Nature 1999402656-60.

8. De Vriese C\& Delporte C. Ghrelin: A new peptide regulating growth hormone release and food intake. International Journal of Biochemistry and Cell Biology2008401420-1424.

9. Ohlsson C, Bengtsson BA, Isaksson OG, Andreassen TT, Slootweg MC. Growth hormone and bone. Endocrine Reviews 19981955-79.

10. Giustina A, Mazziotti G, Canalis E. Growth hormone, insulin-like growth factors, and the skeleton. Endocrine Reviews200829535-559.

11. Le Roith D, Bondy C, Yakar S, Liu JL, Butler A. The somatomedin hypothesis: 2001. Endocrine Reviews20012253-74.

12. Hauschka PV, Lian JB, Cole DE, Gundberg CM. Osteocalcin and matrix Gla protein: vitamin K-dependent proteins in bone. Physiological Reviews1989 69 990-1047.

13. Delemarre-van de Waal HA, van Coeverden SC, Rotteveel J. Hormonal determinants of pubertal growth. Journal of Pediatric Endocrinology and Metabolism2001141521-1526.

14. Eyre DR. Bone biomarkers as tools in osteoporosis management. Spine 19972217-24.

15. Frindik JP, Kemp SF, Hunold JJ. Near adult heights after growth hormone treatment in patients with idiopathic short stature or idiopathic growth hormone deficiency. Journal of Pediatric Endocrinology and Metabolism200316 607-612.

16. Nilsson A, Ohlsson C, Isaksson OG, Lindahl A, Isgaard J. Hormonal regulation of longitudinal bone growth. European Journal of Clinical Nutrition 199448150-160.

17. Rogol AD. Growth hormone: physiology, therapeutic use, and potential for abuse. Exercise and Sport Sciences Reviews198917353-377. 
18. Yilmaz D, Ersoy B, Bilgin E, Gümüşer G, Onur E, Pinar ED. Bone mineral density in girls and boys at different pubertal stages: relation with gonadal steroids, bone formation markers, and growth parameters. Journal of Bone and Mineral Metabolism200523476-482.

19. Norjavaara E, Ankarberg C, Albertsson-Wikland K. Diurnal rhythm of 17 beta-estradiol secretion throughout pubertal development in healthy girls: evaluation by a sensitive radioimmunoassay. Journal of Clinical Endocrinology and Metabolism1996814095-4102.

20. Knip M, Reunanen A, Virtanen SM, Nuutinen M, Viikari J, Akerblom HK. Does the secular increase in body mass in children contribute to the increasing incidence of type 1 diabetes? Pediatric Diabetes2008946-49.

21. Kaaks R \& Lukanova A. Energy balance and cancer: the role of insulin and insulin-like growth factor - I. The Proceedings of the Nutrition Society200160 91-106.

22. Stoll BA \& Secreto G. New hormone-related markers of high risk to breast cancer. Annals of Oncology1992 $3435-438$.

23. Styne DM. The regulation of pubertal growth. Hormone Research20036022-26.

24. Rosen CJ. Insulin-like growth factor I and bone mineral density: experience from animal models and human observational studies. Best practice and research. Clinical Endocrinology and Metabolism 200418423-435.

25. Canalis E\& Lian JB. Effects of bone associated growth factors on DNA, collagen and osteocalcin synthesis in cultured fetal rat calvariae. Bone 19889243-246.

26. Bereket A, Turan S, Omar A, Berber M, Ozen A, Akbenlioglu C, Haklar G. Serum IGF-1 and IGFBP-3 levels of Turkish children during childhood and adolescence: establishment of reference ranges with emphasis on puberty. Hormone Research20066596-105.

27. Achermann JC, Brook CG, Robinson IC, Matthews DR, Hindmarsh PC. Peak and trough growth hormone (GH) concentrations influence growth and serum insulin like growth factor-1 (IGF-1) concentrations in short children. Clinical Endocrinology199950301-308.

28. Yuksel B, Ozbek MN, Mungan NO, Darendeliler F, Budan B, Bideci A, Çetinkaya E, Berberoğlu M, Evliyaoğlu O, Yeşilkaya E, Arslanoğlu İ, Darcan Ş, Bundak R, Ercan O.Serum IGF-1 and IGFBP-3 levels in healthy children between 0 and 6 years of age. Journal of Clinical Research in Pediatric Endocrinology 20113 84-88.

29. Bahrani MA, Ali AA, Al-Samarraie AY. Insulin-like Growth Factor -1 (IGF-1) predict the diagnosis of growth hormone deficiency in short prepubertal children. Iraqi Journal of Pharmaceutical Science20112054-58.

30. Kota SK, Jammula S, Gayatri K, Kota SK, Tripathy PR, Modi KD. IGF-1 and IGFBP 3 in Growth Hormone Deficiency. Role of Insulin like Growth Factor-1 (IGF-1) and IGF Binding Protein 3 in the Diagnosis of Growth Hormone Deficiency: Changing Paradigm. Journal of Nepal Paediatric Society 201232154-162.

31. Bajpai A\& Menon PS. Insulin like Growth Factors Axis and Growth Disorders.Indian Journal of Pediatrics20067367-71.

32. Wacharasindhu S, Supornsilchai V, Aroonparkmongkol S, Srivuthana S. Diagnosis and growth hormone (GH) therapy in children with GH deficiency: experience in King Chulalongkorn Memorial Hospital, Thailand. Journal of the Medical Association of Thailand2007902047-2052.

33. Cumming DC. Exercise-associated amenorrhea, low bone density, and estrogen replacement therapy. Archives of Internal Medicine 19961562193-2195.

34. Wu XY, Yu SJ, Zhang H, Xie H, Luo XH, Peng YQ, Yuan LQ, Dai RC, Sheng ZF, Liu SP, Wu XP, Liao EY. Early bone mineral density decrease is associated with FSH and LH, not estrogen. International Journal of Clinical Chemistry201341569-73.

35. Fleisher GA, Eickelberg ES \& Elveback LR. Alkaline phosphatase activity in the plasma of children and adolescents. Clinical Chemistry 197723 469-72.

36. Round JM, Butcher S \& Steele R. Changes in plasma organic phosphorus and alkaline phosphatase activity during the adolescent growth spurt. Annals of Human Biology1979 6 129-36. 